\title{
Conversion of organic micropollutants with limited bromate formation during the Peroxone process in drinking water treatment
}

\author{
A. H. Knol ${ }^{1}$, K. Lekkerkerker-Teunissen ${ }^{1}$, C. J. Houtman ${ }^{2}$, J. Scheideler ${ }^{3}$, A. Ried ${ }^{3}$, and J. C. van Dijk \\ ${ }^{1}$ Dunea N.V., P.O. Box 756, 2700 AT Zoetermeer, the Netherlands \\ ${ }^{2}$ Het Waterlaboratorium, P.O. Box 734, 2003 RS Haarlem, the Netherlands \\ ${ }^{3}$ Xylem, Boschstrasse 4-14, 32051 Herford, Germany \\ ${ }^{4}$ TU Delft, Stevinweg 1, 2628 CN Delft, the Netherlands
}

Correspondence to: A. H. Knol (t.knol@dunea.nl)

Received: 12 January 2015 - Published in Drink. Water Eng. Sci. Discuss.: 24 March 2015

Revised: 7 June 2015 - Accepted: 17 August 2015 - Published: 17 September 2015

\begin{abstract}
Advanced oxidation with $\mathrm{O}_{3} / \mathrm{H}_{2} \mathrm{O}_{2}$ (peroxone) was conducted on pilot plant scale on pre-treated Meuse river water to investigate the conversion of organic micropollutants (OMPs) and the formation of bromate. Fourteen selected model compounds were dosed to the pre-treated river water on a regular basis to assess the efficiency of the peroxone process and to establish the influence of the water matrix.

The ozone dose was the main factor in the conversion of the model compounds, however, the ozone dose was limited because of bromate formation. The hydrogen peroxide dosage had only a minor effect on the conversion, but it limited the bromate formation effectively. In terms of limited chemical consumption, maximal conversion and to comply the strict Dutch drinking water act for bromate of $1 \mu \mathrm{gL}^{-1}$, a practical peroxone setting was $6 \mathrm{mg} \mathrm{L}^{-1}$ hydrogen peroxide and $1.5 \mathrm{mg} \mathrm{L}^{-1}$ ozone. During the investigation period, the average conversion of the model compounds was $78.9 \%$.

The conversion of OMPs was higher at higher water temperatures and lower concentrations of DOC and bicarbonate. The bromate formation also was higher at higher water temperature and lower bicarbonate concentration and proportional with the bromide concentration, above a threshold of about $32 \mu \mathrm{g} \mathrm{L}{ }^{-1}$ bromide. The peroxone process can be controlled on basis of the (derived) parameters water temperature, bicarbonate and DOC.
\end{abstract}

\section{Introduction}

All over the world surface water is to some extend contaminated with organic micro pollutants (OMPs). It is expected that concentrations of OMPs will increase, due to growth and aging of populations and global warming. In areas with a shortage of groundwater, drinking water companies use the available surface water as source for drinking water production. They are more and more aware of the fact that conventional treatment technologies, such as coagulation, filtration and activated carbon filtration, are not adequate in removing all OMPs from the surface water. The combination of the increasing concentrations of OMPs in surface waters and the inadequate removal of the polar OMPs with conven- tional treatment processes, necessitate research on an additional barrier against OMPs.

Drinking water company Dunea, in the western part of the Netherlands, recognizes the threat of OMPs in their source the Afgedamde Maas (Enclosed Meuse), a side branch of the Meuse River, although the drinking water quality still complies the standards of the Dutch Drinking Water Law, including the standards for OMPs. Managed aquifer recharge (MAR) by dune filtration and the dosing of powdered activated carbon (PAC) are the current barriers against these substances.

Only nonpolar OMPs are well removed by MAR and PAC. Polar OMPs are adsorbed less and/or converted (IJpelaar, 2008). Pharmaceuticals and pesticides are main contami- 
nants detected consistently in the Dutch Meuse River (Houtman et al., 2010). However, the effect on human health at low concentrations is judged negligible (Schriks et al., 2010; Houtman et al., 2014).

Membrane filtration and advanced oxidation (AOP) are the two common technologies to reduce concentrations of OMPs in pretreated surface water. After careful consideration, Dunea chose advanced oxidation as the most optimal technique (Abrahamse et al., 2007) and carried out research with this technology. When AOP is installed before MAR, it is expected that these two processes will provide a synergistic hybrid system (Lekkerkerker-Teunissen et al., 2012).

In comparison with other AOP technologies, the $\mathrm{O}_{3} / \mathrm{H}_{2} \mathrm{O}_{2}$ (or peroxone) process, is known as energy efficient. The two mechanisms to convert OMPs are direct oxidation by ozone and oxidation by in-situ produced hydroxyl radicals $(\cdot \mathrm{OH})$. Although the reaction rate of ozone, depending on the type of compounds, is relatively slow and typically in the range of $k=1.0$ till $10^{6} \mathrm{M}^{-1} \mathrm{~s}^{-1}$ (Gottschalk et al., 2010), and the reaction rate of hydroxyl radicals is much higher and typically in the range of $k=10^{8}$ till $10^{10} \mathrm{M}^{-1} \mathrm{~s}^{-1}$, direct oxidation cannot be neglected when applying peroxone (von Gunten, 2003a). Decomposition of ozone is accelerated by addition of hydrogen peroxide with a reaction rate of $k=1.1 \times 10^{5} \mathrm{M}^{-1} \mathrm{~s}^{-1}$.

The efficiency of peroxone in converting OMPs largely depends on the water quality matrix. Ozone and hydroxyl radicals not only react with OMPs, but also with scavengers as natural organic matter (NOM, mainly humic substances) and bicarbonate (von Gunten, 2003a). Besides that, the water temperature of the Meuse River yearly varies between close to zero to around $25^{\circ} \mathrm{C}$, which influences dissociation coefficients and hydraulic conditions (as mixing energy) in the reactor.

A reaction that is of particular importance is the reaction of ozone with bromide into bromate, since bromate is a suspected carcinogen (Kurokawa et al., 1982). The WHO, EPA and European Drinking Water Directive established a guideline of $10 \mu \mathrm{g} \mathrm{L}^{-1}$ bromate. Two guidelines are mentioned in the Dutch Drinking Water Act: In case of disinfection with ozone, the appointed guideline is $5 \mu \mathrm{g} \mathrm{L}^{-1}$ as a $90 \%$ percentile value with a maximum of $10 \mu \mathrm{g} \mathrm{L}-1$. If ozone is applied for oxidation, the bromate guideline is $1 \mu \mathrm{gL}^{-1}$, which means that applying peroxone can be seen as an ultimate challenge. Nevertheless, the negligible risk level (in the Netherlands defined as the concentration at which one additional case of cancer would occur in one million lifelong exposed people $; 10^{-6}$ ) is even lower and calculated to be $0.2-$ $0.6 \mu \mathrm{g} \mathrm{L}-1$ (WHO, 2005). The target value of this research was an average bromate formation of $0.5 \mu \mathrm{g} \mathrm{L}^{-1}$ with a maximum of $1 \mu \mathrm{g} \mathrm{L}^{-1}$. Also taking into account the concentration levelling MAR after applying peroxone, the bromate concentration in drinking water then will not exceed $0.5 \mu \mathrm{g} \mathrm{L}^{-1}$.
Bromate formation can theoretically be limited by a fast decomposition of ozone and increasing the ratio between the hydrogen peroxide and ozone doses (von Gunten, 2003b).

Bromate formation is thus affected by the varying water matrix parameters $\mathrm{pH}$, water temperature, bromide and bicarbonate. Two other parameters, dissolved organic carbon (DOC, a measurement for natural organic matter) and ammonia, appeared to be not of relevance for the formation of bromate. Bromate is formed proportionally when the ratio of ozone dose and DOC, in $\mathrm{mg} \mathrm{O}_{3} \mathrm{mg} \mathrm{C}^{-1}$, is exceeding 0.4 (Croué et al., 1996; Amy et al., 1993), which is much higher than the applied ratio in this research. The role of ammonia (ammonia can depress the bromate formation) could be neglected, because only in a short period (weeks) the concentration was higher than the detection limit of $0.02 \mathrm{mg} \mathrm{NL}^{-1}$, which is too low for limiting bromate formation.

The goal of this research was to optimise the use of peroxone, restricted by a bromate target value of $0.5 \mu \mathrm{g} \mathrm{L}^{-1}$, considering the maximum ozone doses that can be applied, as well as the ozone/hydrogen peroxide ratio and the corresponding conversion of OMPs. The influence of the water matrix, the ozone dose and the hydrogen peroxide concentration on the bromate formation and the conversion of OMPS were investigated in an on-site pilot plant set-up, accompanied by batch experiments and long term duration experiments.

\section{Materials and methods}

\subsection{Peroxone process installation}

The pilot plant consisted of an ozone loop reactor (Xylem Wedeco) with sequential injection points (IPs) and sample points (SPs) and degassing chamber, and an ozone generator. A schematic view of the loop reactor is plotted in Fig. 1.

The ozone generator had a capacity between 3.5 and $100 \mathrm{~g}$ ozone per hour, produced from oxygen. The minimum dose applicable was $0.7 \mathrm{mg} \mathrm{L}^{-1}$. Hydrogen peroxide $(10 \%$ stock solution) was dosed in the influent water before it entered the loop reactor. Model compounds were dosed before the dosage of hydrogen peroxide. Directly after each dosing point, a static mixer was installed in the pipe. The water velocity in the loop reactor was $1.44 \mathrm{~m} \mathrm{~s}^{-1}$ at design capacity of $5.0 \mathrm{~m}^{3} \mathrm{~h}^{-1}$.

The loop reactor was equipped with a multi ozone dosing system. The ozone was dosed in parts by dividing the gas flow over a number of (maximal 6) IPs. A static mixer was installed after each IP. The pressure drop between two IPs was $1.85 \mathrm{mwc}$ at design capacity. The retention time between the IPs was $1.2 \mathrm{~s}$. Between the IPs, SPs were installed, see Fig. 2. The treated water discharged to a degasser, in which the off gas (oxygen and undissolved ozone) and water were separated. The residence time in this contact chamber was about $25 \mathrm{~s}$. The off gas passed a column in which possible residual ozone was catalytically degraded into oxygen and discharged 


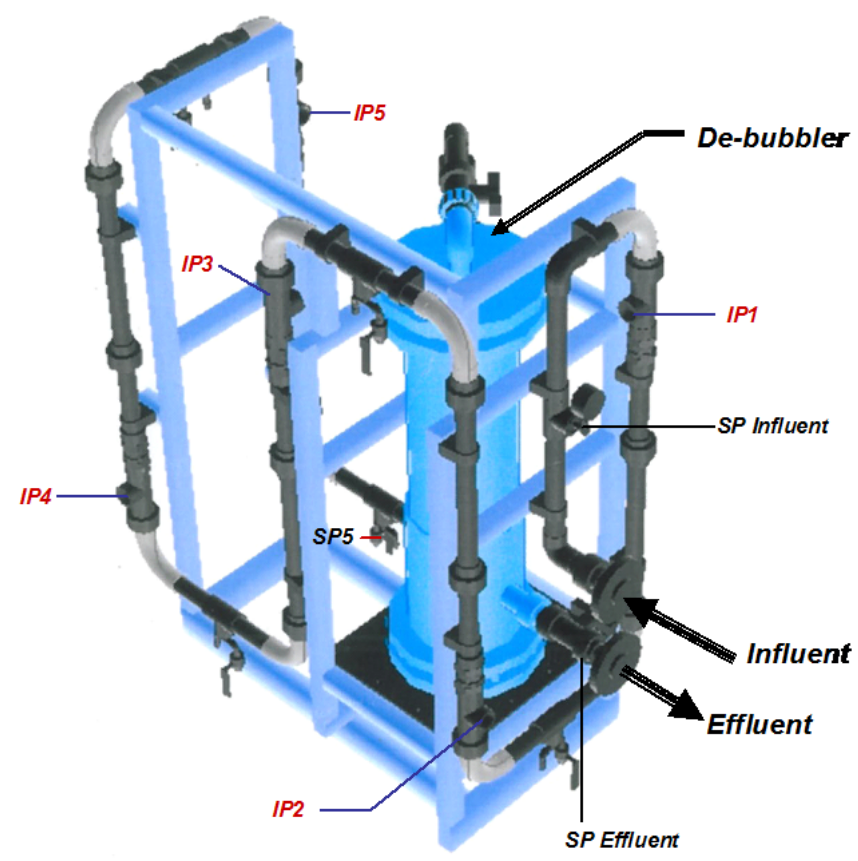

Figure 1. Peroxone loop reactor with injection points (IPs), sample points (SPs) and de-bubbler contact chamber.

outside the building by a ventilator. The treated water was collected in a $10 \mathrm{~m}^{3}$ storage tank and treated several times by additional AOP by circulation till the OMP concentrations were lower than the detection limit before discharge.

The ozone content was measured in the feed gas and in the off gas by an BMT964 ozone analyser. In this way the efficiency of the ozone introduction and reaction was determined. Although six IPs were available in the loop reactor, most of the time only four were used (IPs 3, 4, 5 and 6) to limit pressure drop, by bypassing the first two IPs.

\subsection{Influent water}

The influent water was pre-treated surface water. The source of this water is a dead-end tributary from the Meuse River. In this tributary, with a residence time of several weeks, coagulation is applied. At the intake the water passes micro-strains (mesh width $35 \mu \mathrm{m}$ ). Afterwards dual media rapid sand filtration is applied. The quality of the intake of river water varies over the seasons as a result of meteorological, biological and hydrological influences. The main water constituents of the rapid sand filtrate (RSF) are provided in Table 1.

\subsection{Experiments}

Because of the varying water quality, research over a longer period was required to establish the formation of bromate and conversion of the model compounds. The influence of the varying parameters on the peroxone process was investigated on a regular basis with standard experiments, in which
Table 1. Minimum, maximum and average values of relevant parameters from RSF.

\begin{tabular}{llrrr}
\hline parameter & unit & minimum & average & maximum \\
\hline Temperature & ${ }^{\circ} \mathrm{C}$ & 1.5 & 12.3 & 20.8 \\
pH & - & 7.81 & 7.97 & 8.11 \\
Ammonia & $\mathrm{mg} \mathrm{NH}_{4}^{+} \mathrm{L}^{-1}$ & $<0.02$ & $<0.02$ & 0.09 \\
DOC & $\mathrm{mg} \mathrm{L}^{-1}$ & 3.38 & 4.26 & 5.26 \\
Bromide & $\mathrm{\mu g} \mathrm{L}^{-1}$ & 104 & 119 & 136 \\
Bicarbonate & $\mathrm{mg} \mathrm{L}^{-1}$ & 155 & 175 & 204 \\
\hline
\end{tabular}

Table 2. Settings of the standard experiments.

\begin{tabular}{|c|c|c|}
\hline parameter & unit & settings \\
\hline Capacity & $m^{3} h^{-1}$ & 5.0 \\
\hline Doses peroxide/ozone & $\mathrm{mg} \mathrm{L}^{-1} / \mathrm{mg} \mathrm{L}^{-1}$ & $\begin{array}{l}6 / 0.7 ; 10 / 0.7 ; 6 / 1.0 ; 10 / 1.0 \\
6 / 1.5 ; 10 / 1.5 ; 6 / 2.0 ; 10 / 2.0\end{array}$ \\
\hline Dosing ozone points & - & IP $3,4,5,6$ \\
\hline $\begin{array}{l}\text { Dose rate model } \\
\text { compounds solution }\end{array}$ & $\mathrm{m}^{3} \mathrm{~h}^{-1}$ & 0.068 \\
\hline
\end{tabular}

8 hydrogen peroxide/ozone settings were used, see Table 2 . In this way, design settings were established to apply the peroxone process.

In addition to the standard experiments, spike experiments were performed to investigate the role of bromide in bromate formation.

\subsection{Investigated compounds}

A set of 14 compounds were dosed to the RSF to investigate the conversion of model compounds by peroxone, see Table 3.

The model compounds were selected based on their different sensitivity for direct oxidation by ozone and hydroxyl radicals and their representativity for different kind of organic pollutants in river water.

The model compounds were spiked in concentrations from 5 till $30 \mu \mathrm{g} \mathrm{L}^{-1}$, depending on the detection limit of the compound, dosing at least 95 times the detection limit. The applied OMP concentrations are expected to be sufficiently low to prevent interaction between the OMPs, as well as to assure that the degradation is independent of initial concentrations (Wols et al., 2013). The actual concentration of the model compounds was measured before the loop reactor. The concentration of DOC was only slightly increased by spiking, while the influent varied over the year from $3.5-5.5 \mathrm{mg}$ $\mathrm{CL}^{-1}$.

\subsection{Chemical and physical analyses}

The hydrogen peroxide concentration in water was analysed on site with a Hach DRL 2000 spectrophotometer. The measurement is based on the reaction of hydrogen peroxide with titanium(IV)oxysulphate solution, following DIN 


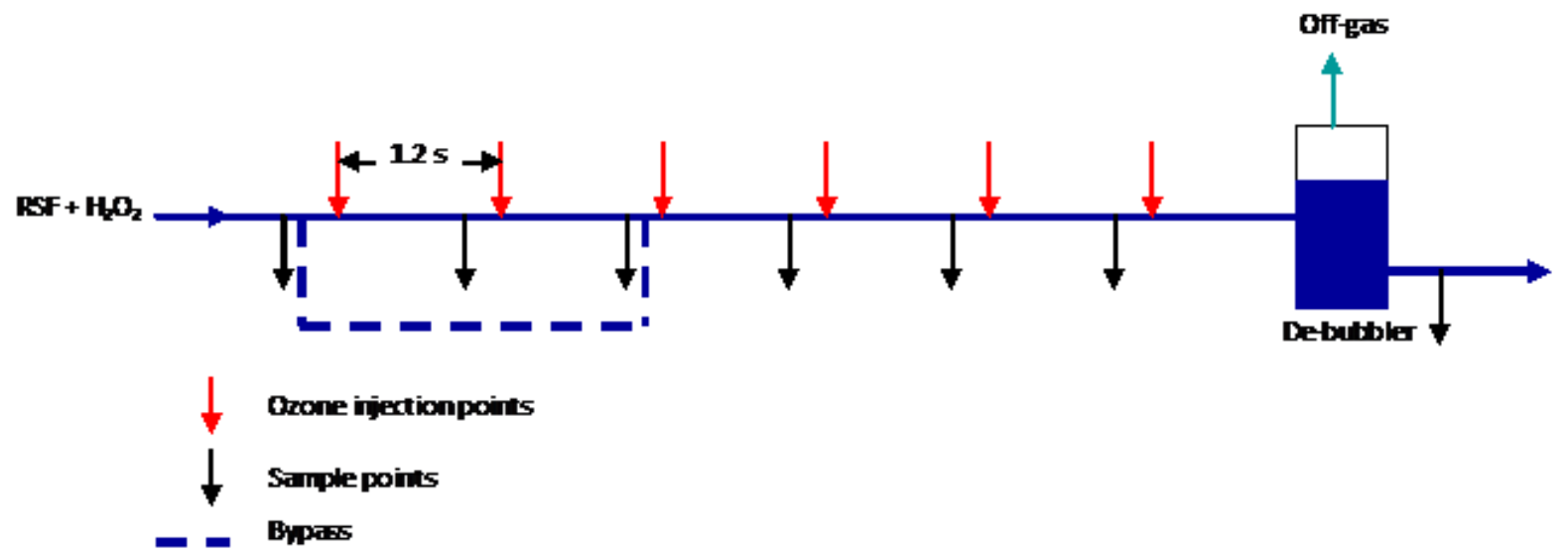

Figure 2. Schematic loop reactor.

Table 3. Average concentration of spiked model compounds in RSF.

\begin{tabular}{lr}
\hline Compound & $\begin{array}{r}\text { Concentration } \\
\left(\mu \mathrm{g} \mathrm{L}^{-1}\right)\end{array}$ \\
\hline Diglyme & 11.0 \\
Bromacil & 10.8 \\
Bentazone & 11.9 \\
Atrazine & 10.1 \\
Isoproturon & 10.2 \\
Ibuprofen & 18.8 \\
Metformin & 4.1 \\
Carbamazepine & 5.7 \\
Metoprolol & 5.4 \\
Trimethoprim & 5.7 \\
Iopromide & 1.8 \\
Phenazone & 5.8 \\
Diclofenac & 31.5 \\
Furosemide & 5.4 \\
\hline
\end{tabular}

38409 H15. The water temperature was measured with a PT 100 element in the main influent.

Analysis of the model compounds was performed with fast analysis methods specially developed for this pilot plant research, i.e. they were (1) suitable to efficiently analyse the large number of samples that were generated in the experiments and (2) had large quantification ranges to enable determination of the removal rate of each model compound under the varying process conditions (LekkerkerkerTeunissen et al., 2012). The methods used an Ultra Performance Liquid Chromatograph (UPLC, Waters Acquity), equipped with a quaternary pump and combined with a Quattro Xevo triple quadrupole Mass Selective Detector (Waters Micromass) with electro spray ionization. $50 \mu \mathrm{L}$ volumes of samples were injected without prior sample preparation. Compounds were measured in three separate runs, slightly differing in eluent composition and gradi- ents. The first run analysed (quantification ranges given between parentheses) atrazine $(0.05-25 \mu \mathrm{g} \mathrm{L}-1)$, bentazone $\left(0.10-25 \mu \mathrm{g} \mathrm{L}{ }^{-1}\right)$, bromacil $\left(0.05-25 \mu \mathrm{gL}^{-1}\right)$, diglyme $(0.15-$ $\left.25 \mu \mathrm{g} \mathrm{L}^{-1}\right)$, ibuprofen $\left(1.5-250 \mu \mathrm{g} \mathrm{L}^{-1}\right)$ and isoproturone $\left(0.05-25 \mu \mathrm{g} \mathrm{L}{ }^{-1}\right)$, all in positive ion mode, except ibuprofen which was measured in negative ion mode. The second run analyzed diclofenac $\left(0.15-150 \mu \mathrm{g} \mathrm{L}^{-1}\right)$, furosemide $(0.025-$ $\left.25 \mu \mathrm{g} \mathrm{L}^{-1}\right)$, metformin $\left(0.005-5 \mu \mathrm{g} \mathrm{L}^{-1}\right)$ and phenazone $\left(0.005-5 \mu \mathrm{g} \mathrm{L}^{-1}\right)$, of which the first two were measured in negative ion mode and metformin and phenazone in positive ion mode. The third run measured carbamazepine $(0.005-$ $\left.5 \mu \mathrm{g} \mathrm{L}^{-1}\right)$, iopromide $\left(0.025-25 \mu \mathrm{gL}^{-1}\right)$, metoprolol $(0.005-$ $\left.5 \mu \mathrm{g} \mathrm{L}^{-1}\right)$ and trimethoprim $\left(0.005-5 \mu \mathrm{g} \mathrm{L}^{-1}\right)$, all in positive ion mode. Quantification was performed using external calibration series of seven concentrations.

Bicarbonate concentrations were determined via titration of hypochloric acid ( $0.1 \mathrm{~N}$ increments) using methyl orange as indicator.

Nitrate concentrations were determined with continuous flow analysis (Skalar $\mathrm{San}^{++}$). Concentrations of ammonium and nitrite were determined with an automated discrete photometric analyzer (Aquakem). Dissolved organic carbon (DOC) concentrations were determined with Non-Purgeable Organic Carbon Analysis (Shimadzu TOC- $\mathrm{V}_{\mathrm{CPH}}$ ). A sample was acidified to a $\mathrm{pH}$ of 2-3 with hypochloric acid and the inorganic carbon was subsequently eliminated with purging gas $\left(\mathrm{O}_{2}\right)$. The remaining total carbon $\mathrm{C}$ was measured and the result is generally referred to as TOC.

UV transmission was measured spectrophotometrically at a wavelength of $254 \mathrm{~nm}$.

Bromate was analysed using ion exchange chromatography followed by conductivity detection (Dionex IonPac AS9SC). The measured bromate concentration was confirmed using a two point calibrated UV absorption measurement at a wavelength of $200 \mathrm{~nm}$. The reporting limit of bromate was $0.5 \mu \mathrm{g} \mathrm{L}^{-1}$, although values higher than the detection limit $\left(0.1 \mu \mathrm{g} \mathrm{L}{ }^{-1}\right)$ were also evaluated to assess the bro- 


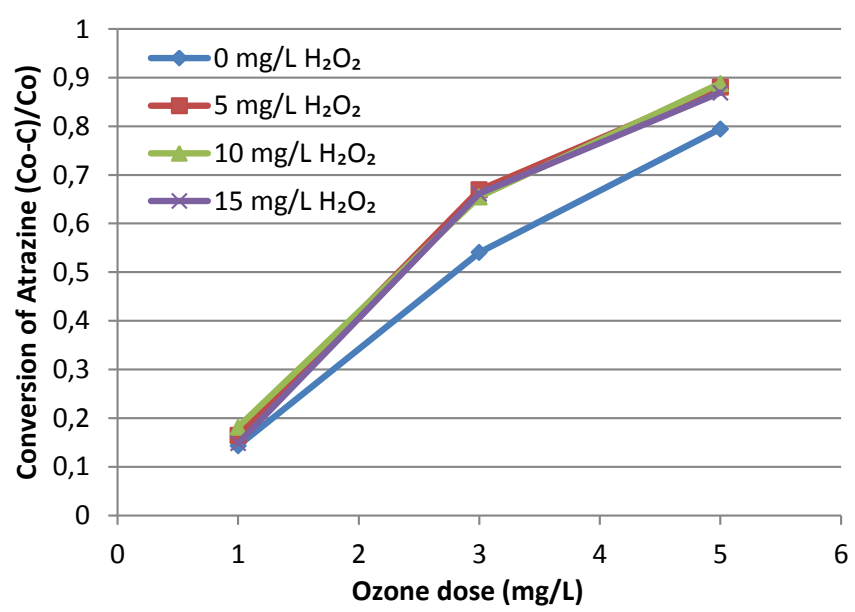

Figure 3. Conversion of atrazine at different settings of the peroxone process $\left(\mathrm{Br}^{-} 124 \mu \mathrm{g} \mathrm{L}^{-1}, \mathrm{HCO}_{3}^{-} 158 \mathrm{mg} \mathrm{L}^{-1}\right.$, DOC 3, $70 \mathrm{mg}$ $\mathrm{CL}^{-1}$, water temperature $11.9^{\circ} \mathrm{C}$ ).

mate formation, because the reporting limit was equal to the bromate target value.

\section{Results and discussion}

\subsection{Proof of principle}

Atrazine was used to investigate the sensitivity for the peroxone process. The conversion increased with the ozone dose, see Fig. 3.

At a dose of $5 \mathrm{mg} \mathrm{L}^{-1}$ ozone, about $80 \%$ of atrazine was converted. By adding $5 \mathrm{mg} \mathrm{L}^{-1}$ hydrogen peroxide, the conversion reached almost $90 \%$. Increase of the hydrogen peroxide dose above $5 \mathrm{mg} \mathrm{L}^{-1}$ did not influence the conversion.

The energy consumption necessary to produce $5 \mathrm{~g}$ ozone to treat $1 \mathrm{~m}^{3}$ water was about $0.045 \mathrm{kWh}$. To achieve a similar atrazine conversion with a comparable pretreated surface water by applying $\mathrm{UV} / \mathrm{H}_{2} \mathrm{O}_{2}$, with the same hydrogen peroxide dose, the energy consumption in order to generate UV radiation is at least ten times higher (Lekkerkerker-Teunissen et al., 2013), which demonstrates the energy efficiency of the peroxone process.

Bromate formation also increased with the ozone dose, see Fig. 4.

However, by adding hydrogen peroxide, bromate formation was limited and the limitation was more when the ratio peroxide/ozone was higher. This observation is in line with findings of (von Gunten et al., 2003b). From Figs. 3 and 4 can be concluded, that the ozone dose is the main factor in converting atrazine and that the hydrogen peroxide dose is the main factor in limiting the bromate formation. Almost $90 \%$ of atrazine was converted with $5 \mathrm{mg} \mathrm{L}^{-1}$ ozone and at least $10 \mathrm{mg} \mathrm{L}^{-1}$ hydrogen peroxide, without exceeding the WHO guideline for bromate of $10 \mu \mathrm{g} \mathrm{L}^{-1}$. To comply a bro-

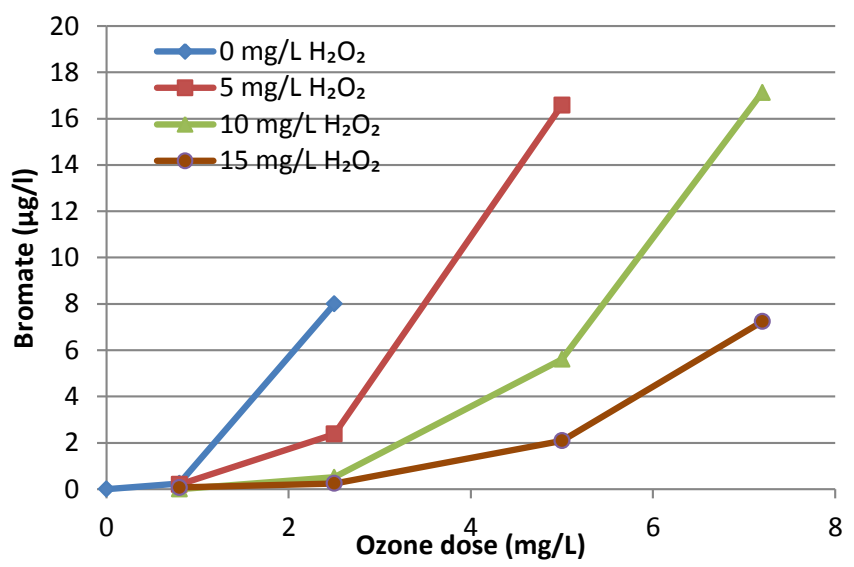

Figure 4. Bromate formation at different settings of the peroxone process $\left(\mathrm{Br}^{-} 126 \mu \mathrm{g} \mathrm{L}^{-1}, \mathrm{HCO}_{3}^{-} 159 \mathrm{mg} \mathrm{L}^{-1}\right.$, DOC $3,26 \mathrm{mg}$ $\mathrm{CL}^{-1}$, water temperature $9.7^{\circ} \mathrm{C}$ ).

mate concentration below $0.5 \mu \mathrm{g} \mathrm{L}^{-1}$ at an ozone dose of $5 \mathrm{mg} \mathrm{L}^{-1}$, even $15 \mathrm{mg} \mathrm{L}^{-1}$ hydrogen peroxide is not enough.

\subsection{Bromate formation}

In the period August 2011 up to and including March 2012, every other week peroxone dosing was investigated with standard experiments. The bromate concentrations are shown in Fig. 5. Because the pilot plant settings were similar during the experiments, differences in bromate formation were caused by variations in the water matrix.

As seen before (Knol, 2000), the influent water can contain low background concentrations of bromate. Figure 5 shows the bromate concentrations formed at different ozone/peroxide settings for the standard experiments over the test period. The curves show similar shapes, only the bromate values differed at the same settings. The bromate formation increased with increasing ozone dose and was reduced by increasing the hydrogen peroxide dose at a given ozone dose. Minimum bromate formation occurred in winter season, maximum bromate formation in summer season.

Only the peroxone settings with the high ozone dose of $2.0 \mathrm{mg} \mathrm{L}^{-1}$, with either 6 or $10 \mathrm{mg} \mathrm{L}^{-1}$ peroxide, exceeded the value of $0.5 \mu \mathrm{g} \mathrm{L}^{-1}$ (with a maximum of $1.0 \mu \mathrm{g} \mathrm{L}^{-1}$ ). Minimal dose of $6 \mathrm{mg} \mathrm{L}^{-1}$ hydrogen peroxide combined with ozone doses up to $1.0 \mathrm{mg} \mathrm{L}^{-1}$ limited the bromate concentration without exception below $0.5 \mu \mathrm{g} \mathrm{L}^{-1}$. The bromate concentrations at setting 6/1.5 varied over the test period from 0.27 till $0.69 \mu \mathrm{g} \mathrm{L}^{-1}$, with an average value of $0.41 \mu \mathrm{g} \mathrm{L}^{-1}$. Thus a safe optimal setting concerning the bromate formation was found as $6 \mathrm{mg} \mathrm{L}^{-1}$ hydrogen peroxide and $1.5 \mathrm{mg} \mathrm{L}^{-1}$ ozone. 


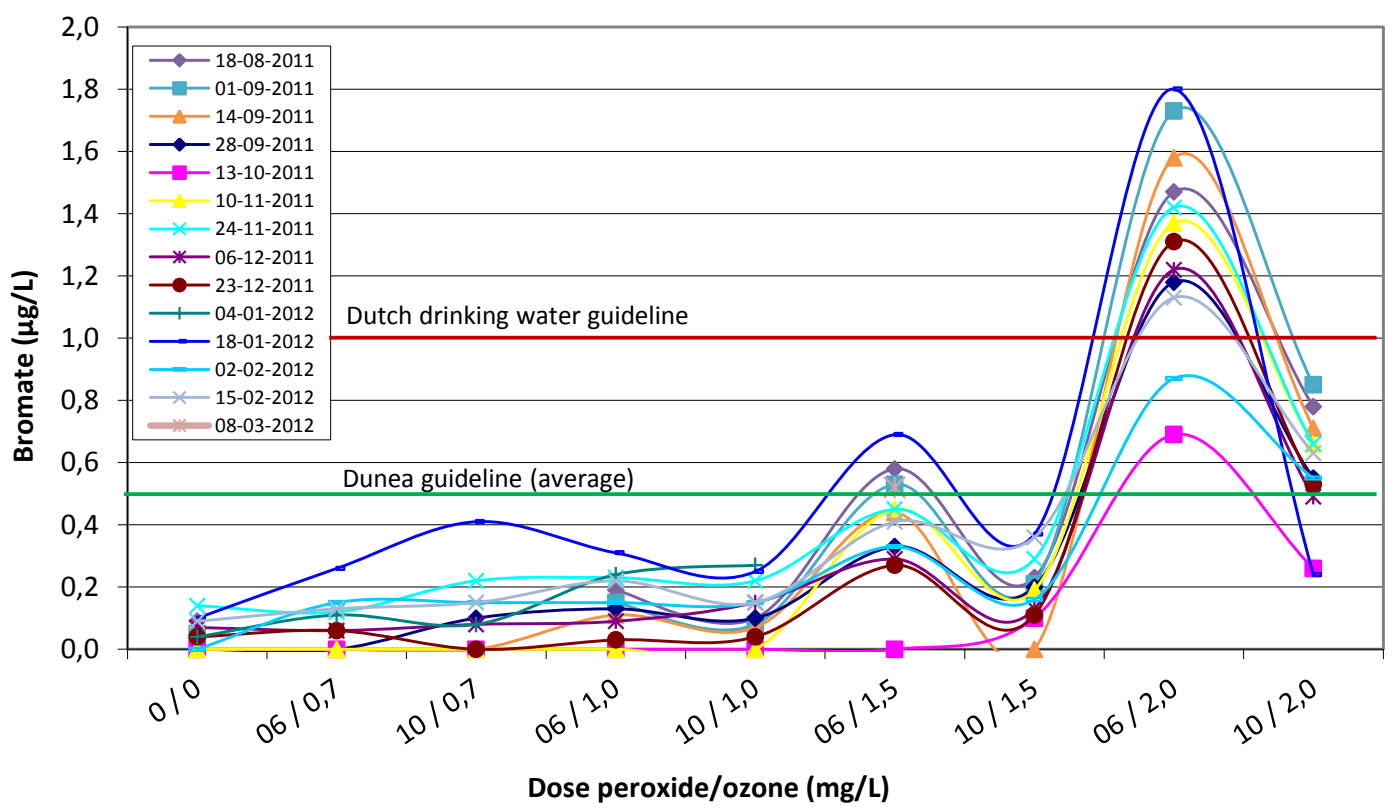

Figure 5. Bromate concentration at standard settings ( $n=14$, August 2011 up to and including March 2012, data points are connected to improve the interpretation).

\subsection{Influence water matrix on bromate formation}

To indicate the responsible parameter(s) for the variation in bromate concentration, the measured values of water temperature, bromide, bicarbonate and $\mathrm{pH}$ of RSF are plotted against bromate of setting 6/2.0 during the test period, Fig. 6 .

The correlations in Fig. 6 are not strong, but certainly trends are visible: the bromate concentration increased with increasing water temperature and bromide concentration and decreasing bicarbonate concentration and $\mathrm{pH}$.

Increase of bromate concentrations with increasing water temperature was expected (Croué et al., 1996; von Gunten, 2003b). Croué et al. reported an increase of $10 \%$ per $10^{\circ} \mathrm{C}$, von Gunten even about $20 \%$ per $10^{\circ} \mathrm{C}$. The variation measured in this study was between 17 and $34 \%$ which is in line with previous research, regarding the $17^{\circ} \mathrm{C}$ temperature difference between the measured minimum and maximum temperature during the standard experiments. The bromate concentration increased with increasing bromide concentration which is expected at bromide concentrations higher than $20 \mu \mathrm{g} \mathrm{L}{ }^{-1}$ (Gottschalk et al., 2010). The bromate concentration decreased with increasing bicarbonate concentration. Bicarbonate is a known scavenger of hydroxyl radicals, so probably less radicals are available to react with bromide. Decreasing bromate formation with increasing $\mathrm{pH}$ is not in line with theory (von Gunten 2003b). However, the variation in $\mathrm{pH}$ during the standard experiments was small with a bandwidth of 0.19 units (7.81-8.00).

Probably the water temperature and the bicarbonate concentration strengthen each other. With increasing water temperature, the bicarbonate concentration decreased, Fig. 7, both resulting in an increased bromate formation. No other correlations were found between the parameters water temperature, $\mathrm{pH}$ and the concentrations of bromide and bicarbonate under tested conditions.

For a better insight in the role of bromide in the bromate formation, concerning the forecasted increase in concentration in the Meuse River in global warming scenarios, this parameter is independently changed by spiking in RSF. The actual bromide concentration in the influent of $130 \mu \mathrm{g} \mathrm{L}^{-1}$ was increased to 270 and $560 \mu \mathrm{g} \mathrm{L}^{-1}$, Fig. 8 .

Bromate formation strongly increased with increasing bromide concentration. It is therefore of importance to limit industrial spills and discharges of bromide in the main stream of the River Meuse, which are held accountable for about two-thirds of the bromide load in the Meuse (Volz, 2013). Based on the equation in Fig. 8, a provisional bromide threshold of $32 \mu \mathrm{g} \mathrm{L}{ }^{-1}(0.24 / 0.0075)$ can be calculated. This value compares to the earlier mentioned $20 \mu \mathrm{g} \mathrm{L}^{-1}$ as reported by Gottschalk et al. (2010).

\subsection{Conversion of organic micropollutants}

The average conversion of fourteen model compounds at the four different ozone dosages ( 0.7 to $2.0 \mathrm{mg} \mathrm{L}^{-1}$ ) and at a peroxide concentration of $6 \mathrm{mg} \mathrm{L}^{-1}$ is shown in Fig. 9. Conversions varied between compounds. Eliminations between less than 10 to over $95 \%$ were observed. Reactivity of organic compounds towards ozone is strongly dependent on the molecular structure of compounds. Electron rich moieties such as aromatic rings and $\mathrm{C}=\mathrm{C}$ double bonds are main reaction sites at which ozone attacks (Sonntag et al., 2012; 

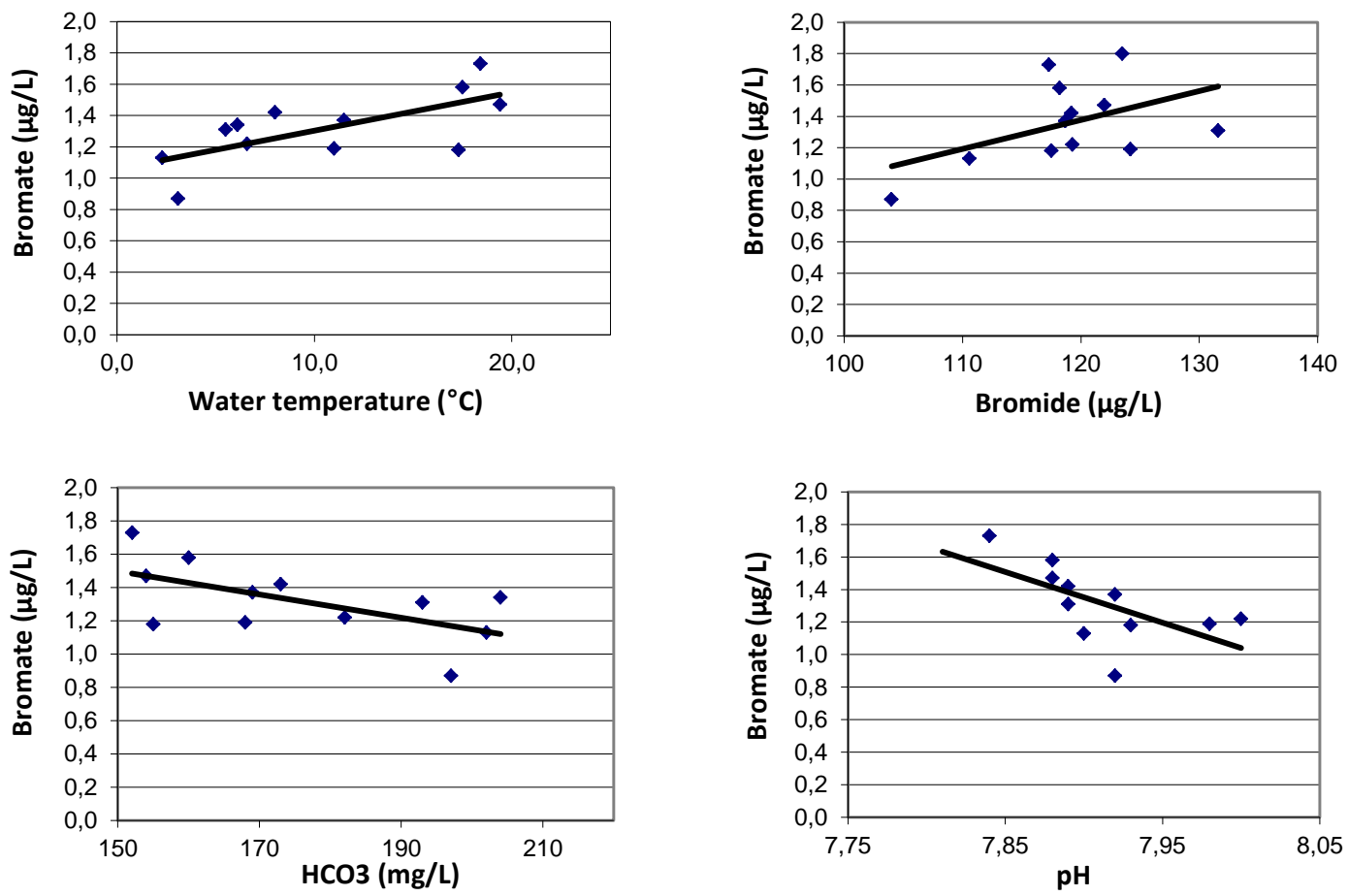

Figure 6. Water temperature, bromide, bicarbonate and $\mathrm{pH}$ vs. bromate concentration.

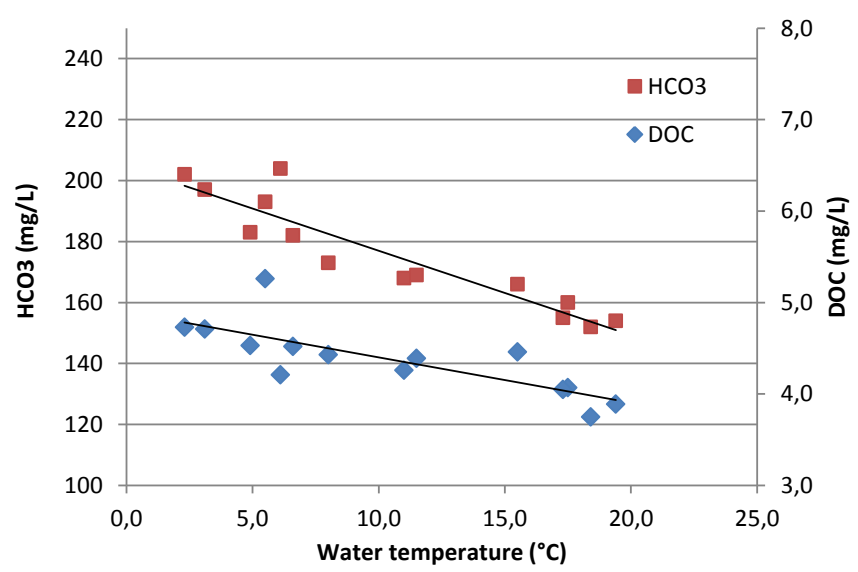

Figure 7. Correlation between water temperature, DOC and bicarbonate concentration.

Ternes et al., 2002). This structure dependency was clearly reflected in the results of the model compounds.

Lowest conversions were found for the model compounds metformin, atrazine, iopromide and diglyme, at the left part of Fig. 9. With the exception of iopromide, these compounds all lack aromatic rings and unsaturated $\mathrm{C}-\mathrm{C}$ bonds. Their limited conversion is in line with results published by Acero et al. (2001) who found that compounds without aromatic and double bond structures, like MTBE, are poorly oxidizable by ozone alone. Iopromide, an X-ray contrast agent also contains one aromatic ring, but this ring is substituted at all six

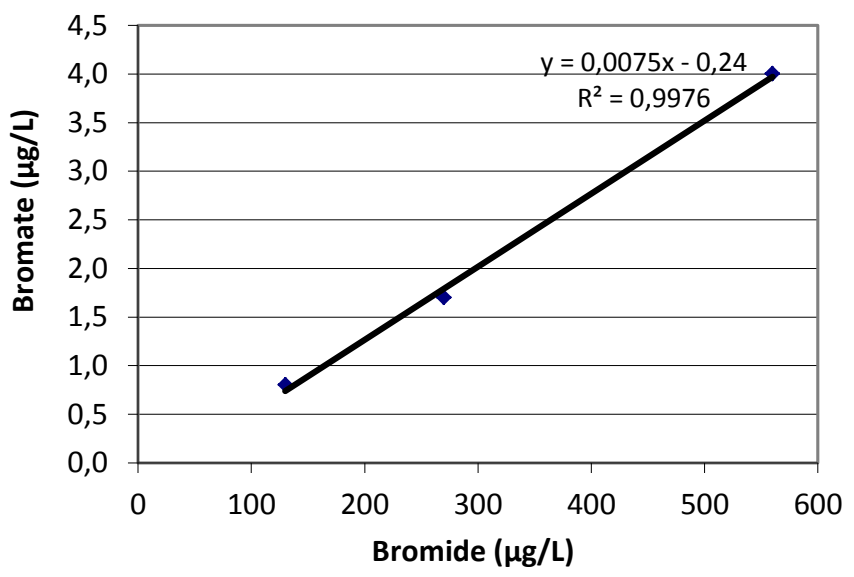

Figure 8. Bromate formation as function of bromide concentration at setting $6 / 1.5$ (water temperature $1.6^{\circ} \mathrm{C}$, bicarbonate $201 \mathrm{mg} \mathrm{L}^{-1}$ ).

C positions (a.o. with three jodine atoms) and therefore not easily oxidized.

Higher conversions, between 38 and $68 \%$ at $0.7 \mathrm{mg} \mathrm{L}^{-1}$ ozone and between 85 and $99 \%$ at $2.0 \mathrm{mg} \mathrm{L}^{-1}$ ozone, were obtained for ibuprofen, metoprolol, bentazone, isoproturon and phenazone.. These five compounds all possess one aromatic ring that is not substituted with halogens at which ozone can attack.

Furosemide, converted for about $95 \%$ at all tested ozone doses, has one aromatic ring in its structure, together with 


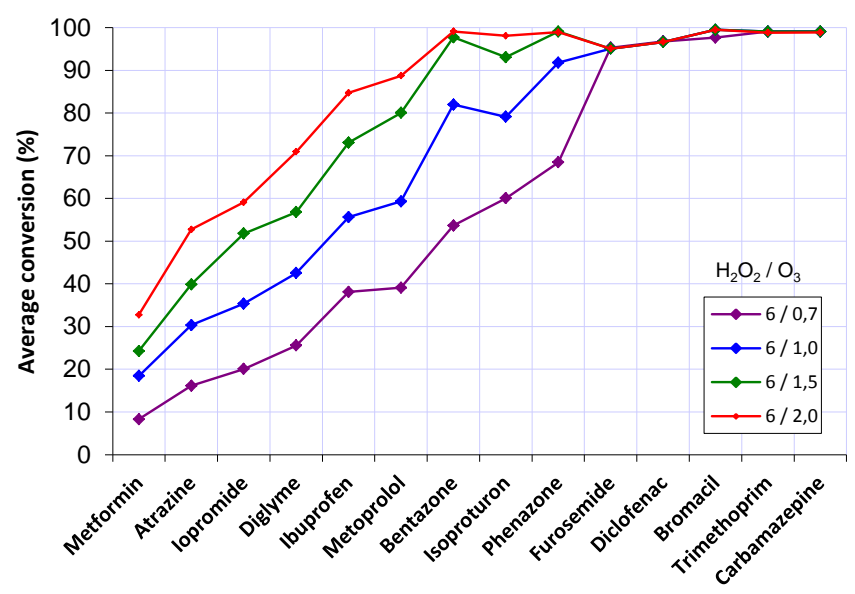

Figure 9. Average $(n=14)$ conversion in percentages of model compounds as function of ozone dosage at a hydrogen peroxide concentration of $6 \mathrm{mg} \mathrm{L}^{-1}$ in the period August 2011 till March 2012.

two $\mathrm{C}=\mathrm{C}$ double bonds. In addition, furosemide has an aromatic amine-N, which also acts as electron rich reaction site for ozone (Lee et al., 2014).

Highest conversions $(\geq 97 \%)$ were observed for diclofenac, trimethoprim and carbamazepine, due to the presence of two oxidizable aromatic rings in their structures. For diclofenac and carbamazepine, this is in line with Ternes et al. (2002).

The high conversion of bromacil is surprising regarding the fact that this herbicide does not have aromatic rings in its structure. It however does possess a bromine substituted $\mathrm{C}=\mathrm{C}$ bond. Bromacil was thus directly oxidized by the attack of ozone on this $\mathrm{C}=\mathrm{C}$ bond and the consecutive loss of bromine (Hapeman et al., 1997). This reaction is energetically favorable due to the fact that bromine acts as a very good leaving group and renders the conversion rate of bromacil comparable to that of the easily oxidizable model compounds with aromatic rings.

The conversion of the model compounds was also assessed at $10 \mathrm{mg} \mathrm{L}^{-1}$ peroxide. The influence of an increased hydrogen peroxide concentration at the same ozone dose on the conversion was however found to be small. In fact, in all cases the average conversion was equal or lower, with a maximum of $4 \%$ decrease at a dose of $1.5 \mathrm{mg} \mathrm{L}^{-1}$ ozone. This is in line with findings published previously for bromacil (Hapeman et al., 1997) and for compounds in hospital waste water effluent (Lee et al., 2014).

Two mechanisms could have been responsible for this phenomenon. Firstly, decomposition of the ozone is accelerated at a higher hydrogen peroxide dosage, which is a disadvantage for compounds that are sensitive for direct oxidation by ozone, and, secondly, excessive peroxide itself can act as a scavenger for hydroxyl radicals.
In general, the conversion of the model compounds was higher with higher ozone dosage. The conversion of the easily oxidizable compounds furosemide, diclophenac, bromocil, trimethoprim and carbamazepine already was maximal at the lowest dosage of $0.7 \mathrm{mg} \mathrm{L}^{-1}$. The conversion of the remaining compounds improved considerably by enhancing the ozone dosage to $2.0 \mathrm{mg} \mathrm{L}^{-1}$. Although from the perspective of micropollutant conversion a dosage of $2 \mathrm{mg} \mathrm{L}^{-1}$ would be optimal, the bromate formation at this setting exceeded the value of $0.5 \mu \mathrm{g} \mathrm{L}^{-1}$. The setting of $6 / 1.5 \mathrm{com}-$ bined acceptable bromate formation with an average conversion of the model compounds of $78.9 \%$ ( $\sigma 24.8 \%)$.

It should therefore be noted that the peroxone process, like all advanced oxidation processes, does not provide a full solution for the problem of OMPs in water sources. Also because oxidation by peroxone leads to the formation of degradation products of OMPs instead of to full mineralisation, e.g. Escher et al. (2009); Sonntag et al. (2012), that may have unwanted toxic properties.

For these reasons, the peroxone process should preferably not be implemented as the only strategy for the removal of OMPs, but in combination with other techniques, in this case followed by biological degradation during MAR and adsorption during PAC filtration.

\subsection{Influence of the water matrix on OMP conversion}

Using the collected data of the standard experiments, the relevant water quality parameters of the influent are plotted against the conversion of the model compounds for which the observed conversion was less than $90 \%$ (Fig. 10).

The conversion of OMPs increased with increasing water temperature and decreasing concentrations of DOC and bicarbonate. The bromate formation increased with increasing water temperature and bicarbonate concentration. Furthermore, the conversion of OMPs and bromate formation increased with ozone dose and the bromate formation was reduced by increasing the dose of hydrogen peroxide. Therefore, the conversion of OMPs and bromate formation can be levelled by adjusting the ozone and hydrogen peroxide doses to water temperature, DOC and bicarbonate: In winter period the conversion of OMPs can be increased by increasing the ozone dose without exceeding the target bromate value and in summer period the bromate formation can be reduced by increasing the hydrogen peroxide dose, without effect on the conversion of OMPs. Controlling peroxone on basis of the online measured or derived parameters as water temperature, bicarbonate and DOC is feasible.

\section{Conclusions}

Advanced oxidation with $\mathrm{O}_{3} / \mathrm{H}_{2} \mathrm{O}_{2}$ was conducted on pilot plant scale on pre-treated Meuse river water to investigate the conversion of 14 selected organic micropollutants and the formation of bromate. The peroxone process effi- 

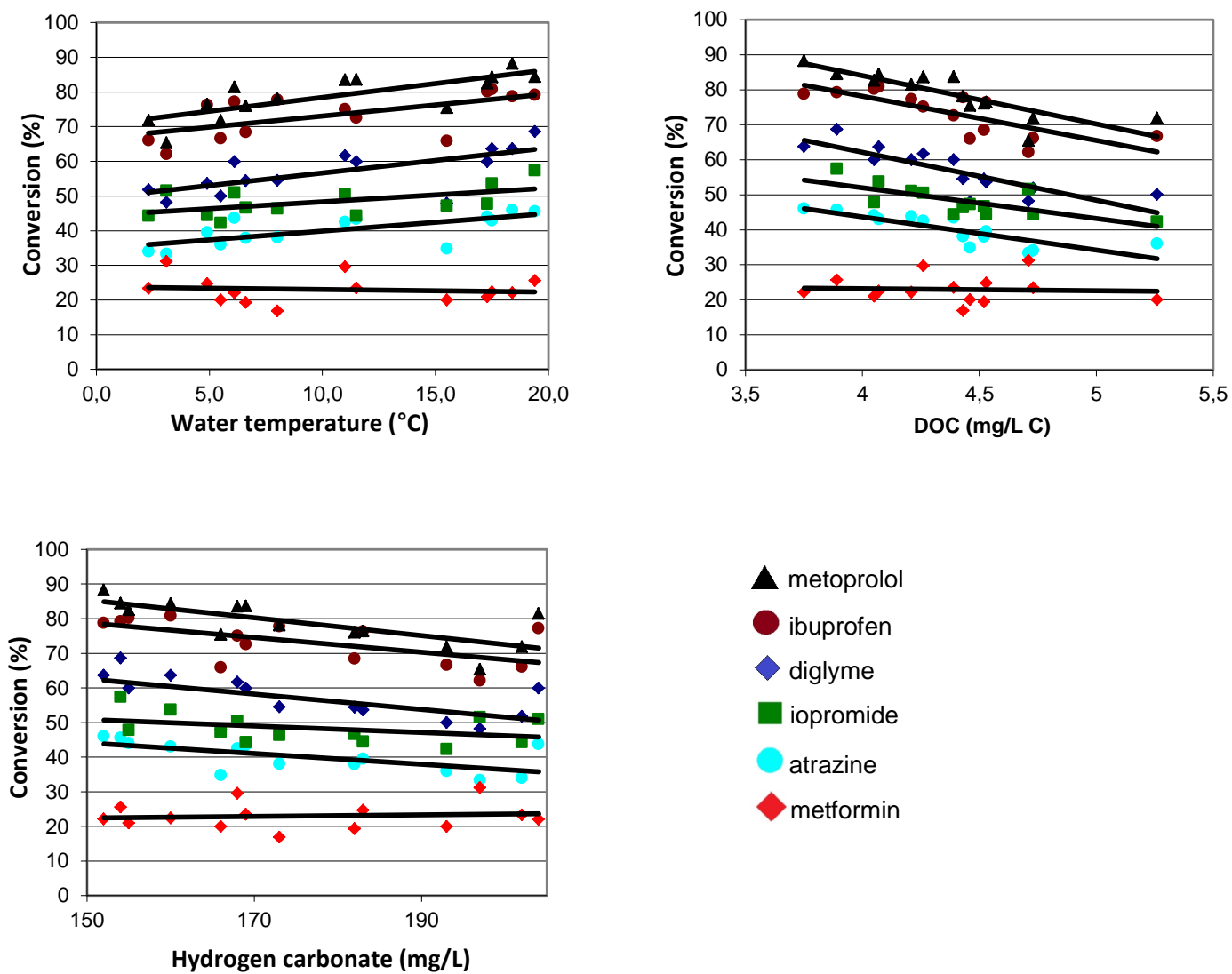

Figure 10. Conversion of compounds versus water temperature and DOC and bicarbonate concentration.

ciently degraded organic micropollutants with aromatic rings and/or unsaturated C-C bonds in their molecular structures. As many OMPs contain these features, the peroxone process might be a useful technique in the purification of contaminated surface water. The dosage of ozone, and with that the conversion of OMPs, is limited due to the bromate formation. Nevertheless an average conversion of 14 model compounds of well over $70 \%$ was achieved with $6 \mathrm{mg} \mathrm{L}^{-1}$ peroxide and $1.5 \mathrm{mg} \mathrm{L}^{-1}$ ozone. The applied ozone dose was the main factor in the conversion of the model compounds. The hydrogen peroxide dosage had only a minor effect on the conversion, but limited the bromate formation effectively to levels below $0.5 \mu \mathrm{g} \mathrm{L}-1$.

The peroxone process can be controlled on basis of the (derived) parameters water temperature, bicarbonate and DOC. Analyses of bromate then can be used to adjust the process.

Acknowledgements. The authors would like to thank the staff of treatment location Bergambacht for their technical support.

Edited by: L. Rietveld

\section{References}

Abrahamse, A. J., IJpelaar, G. F., and Knol, A. H.: Project Uitbreiding Zuivering DZH, optionele technieken en locatie keuze, KWR, Dunea, 2007.

Acero, J. L., Haderlein, S. B., Schmidt, T. C., Suter, M. J. F., and von Gunten, U.: MTBE oxidation by conventional ozonation and the combination ozone/hydrogen peroxide: efficiency of the processes and bromate formation, Environ. Sci. Technol., 35, 42524259, 2001.

Amy, G., SiddiQui, M., Ozekin, K., and Westerho, P.: Treshold levels for bromate formation in drinking water, in: Proc. ISWA/AIDE International Workshop Bromate and water treatment, Paris, 22-24 November 1993, 169-180, 1993.

Croué, J. P., Koudjonou, B. K., and Legube, B.: Parameters affecting the formation of bromate ion during ozonation, Ozone Sci. Engin., 18, 1-18, 1996.

Escher, B. I., Bramaz, N., and Ort, C.: JEM spotlight: monitoring the treatment efficiency of a full scale ozonation on a sewage treatment plant with a mode-of-action based test battery, J. Environ. Monitor., 11, 1836-1846, 2009.

Gottschalk, C., Libra, J. A., and Saupe, A.: Ozonation of Water and Waste Water, a Practical Guide to Understanding Ozone and its Application, 2nd Edn., 2010.

Hapeman, C. J., Anderson, B. G., Torrents, A., and Acher, A. J.: Mechanistic investigations concerning the aqueous ozonolysis of bromacil, J. Agr. Food Chem., 45, 1006-1011, 1997. 
Houtman, C. J.: Emerging contaminants in surface waters and their relevance for the production of drinking water in Europe, J. Integr. Environ. Sci., 1-25, 2010.

Houtman, C. J., Kroesbergen, J., Lekkerkerker-Teunissen, K., and van der Hoek, J. P.: Human health risk assessment of the mixture of pharmaceuticals in Dutch drinking water and its sources based on frequent monitoring data, Sci. Total Environ., 496, 5462, 2014.

IJpelaar, G.: Robuustheid van de Zuivering bij DZH, Management Samenvatting Prioritaire Stoffen, 2005-2007, Kiwa Water Research, 2008.

Knol, A. H.: Gedrag van Bromaat in de Zuivering van Maas Tot Drinkwater, Duinwaterbedrijf Zuid-Holland, 2000.

Kurokawa, Y., Hayashi, Y., Maekawa, A., Takahashi, M., and Kokubo, T.: Induction of renal cell tumors in F-344 rats by oral administration of potassium bromate, A Food Additive, Gann, 73, 335-338, 1982.

Lee, Y., Kovalova, L., McArdell, C. S., and von Gunten, U.: Prediction of micropollutant elimination during ozonation of a hospital wastewater effluent, Water Res., 64, 134-148, 2014.

Lekkerkerker-Teunissen, K., Knol, A. H., Scheideler, J., Ried, A., Verberk, J. Q. J. C., and van Dijk, J. C.: Serial ozone-AOP and UV-AOP for synergistic and effective organic micropollutant treatment and bromate formation control, Sep. Purif. Technol., 100, 22-29, 2012.

Lekkerkerker-Teunissen, K., Knol, A. H., Derks, J. G., Heringa, M. B., Houtman, C. J., Hofman-Caris, C. H. M., Beerendonk, E. F., Reus, A., Verberk, J. Q. J. C., and van Dijk, J. C.: Pilot plant results with three different types of lamps for advanced oxidation, Ozone Sci. Engin., 35, 38-48, 2013.
Schriks, M., Heringa, M. B., van der Kooij, M. M. E., de Voogt, P., and van Wezel, A. P.: Toxicological relevance of emerging contaminants for drinking water quality, Water Res., 44, 461476, 2010.

Sonntag, C. and von Gunten, U.: Chemistry of Ozone in Water and Wastewater Treatment: From Basic Principles to Applications, IWA Publishing, 2012.

Ternes, T. A., Meisenheimer, M., McDowell, D., Sacher, F., Brauch, H. J., Haist-Gulde, B., Preuss, G., Wilme, U., and Zulei-Seibert, N.: Removal of pharmaceuticals during drinking water treatment, Environ. Sci. Technol., 36, 3855-3863, 2002.

Volz, J.: Bromidebronnen in Het Stroomgebied van de Maas, Een Kwalitatieve en Kwantitatieve Verkenning, 21 Maart 2013.

von Gunten, U.: Ozonation of drinking water: Part I. Oxidation kinetics and product formation, Water Res., 37, 1443-1467, 2003a.

von Gunten, U.: Ozonation of drinking water: Part II. Disinfection and by-product formation in presence of bromide, iodide and chlorine, Water Res., 37, 1469-1487, 2003b.

WHO: Bromate in Drinking Water, Background Document for Development of WHO Guidelines for Drinking-water Quality, (WHO/SDE/WSH/05.08/78), 2005.

Wols, B. A., Hofman-Caris, C. H. M., and Beerendonk, E. F.: Degradation of 40 selected pharmaceuticals by $\mathrm{UV} / \mathrm{H}_{2} \mathrm{O}_{2}$, Water Res., 47, 5876-5888, doi:10.1016/j.watres.2013.07.008, 2013. 